\title{
Dynamics in the polar thermosphere after the coronal mass ejection of 28 October 2003 observed with the EPIS interferometer at Svalbard
}

\author{
G. Thuillier, ${ }^{1}$ J.-M. Perrin, ${ }^{2}$ C. Lathuillère, ${ }^{3}$ M. Hersé, ${ }^{1}$ T. Fuller-Rowell, ${ }^{4,5}$ \\ M. Codrescu, ${ }^{4,5}$ F. Huppert, ${ }^{2}$ and M. Fehrenbach ${ }^{2}$ \\ Received 7 December 2004; revised 12 May 2005; accepted 9 June 2005; published 30 September 2005.
}

[1] The upper atmosphere dynamics in the polar cap is mainly driven by ion-drag momentum sources imposed by the mapping of magnetosphere convection into the thermosphere/ionosphere and by Joule and auroral particle heating. Auroral particles also enhance conductivity particularly in the middle and lower ionosphere. Changes in the magnetospheric energy and momentum sources can significantly modify the wind circulation during geomagnetic storms. To observe these effects, a Michelson interferometer has been installed in Svalbard to measure winds in the thermosphere. Prior to 30 October 2003, cloud cover over Svalbard rendered the conditions unfavorable for optical observation. However, meteorological conditions improved after this date to enable the thermospheric response to the 28 October coronal mass ejection to be made. During quiet geomagnetic conditions measured wind velocities were in good agreement with those predicted by the Horizontal Wind Model (HWM). During disturbed geomagnetic conditions, HWM tended to underestimate the observed velocities. Comparison of the wind observations with a physical model tended to show reasonable agreement during both the strongly driven and recovery phase of the storm. Although the physical model did not always capture the timing of the rapid changes in the wind response in the early phase of the storm, the amplitudes of the fluctuations were in good agreement. After the initial phase the physical model agreed well with both the timing and amplitude of the meridional and zonal wind fluctuations. The meridional wind component was also derived from the EISCAT Svalbard Radar ion velocity and was found to be in close agreement with the optical winds observations.

Citation: Thuillier, G., J.-M. Perrin, C. Lathuillère, M. Hersé, T. Fuller-Rowell, M. Codrescu, F. Huppert, and M. Fehrenbach (2005), Dynamics in the polar thermosphere after the coronal mass ejection of 28 October 2003 observed with the EPIS interferometer at Svalbard, J. Geophys. Res., 110, A09S37, doi:10.1029/2004JA010966.

\section{Introduction}

\subsection{Observations in the Polar Cap Thermosphere}

[2] At high latitudes the magnetospheric convection electric field maps efficiently to the thermosphere and ionosphere. The convection electric field sets the ionospheric plasma into motion and, through collisions with the neutral atmosphere, can drive high velocity thermospheric winds. Auroral particle precipitation accompanies the electrodynamic interaction between the magnetosphere and ionosphere, increasing ion density and conductivity. Joule heating, from the dissipation of the current flow, and direct auroral particle precipitation both contribute to the heating at high latitudes, which can further drive changes in

\footnotetext{
${ }^{1}$ Service d'Aéronomie du Centre National de la Recherche Scientifique, Verrières-le-Buisson, France.

${ }^{2}$ Observatoire de Haute Provence, St Michel l'Observatoire, France.

${ }^{3}$ Laboratoire de Planétologie de Grenoble, Grenoble, France.

${ }^{4}$ Cooperative Institute for Research in Environmental Sciences, University of Colorado, Boulder, Colorado, USA.

${ }^{5}$ Also at Space Environment Center, NOAA, Boulder, Colorado, USA.

Copyright 2005 by the American Geophysical Union. 0148-0227/05/2004JA010966
}

neutral winds. The combined input of energy and momentum at high-latitude modifies temperature, composition, and dynamics in the thermosphere and ionosphere. This paper is an attempt to quantify the response of the upper atmosphere dynamics to geomagnetic perturbations and investigate the associated mechanisms by using a physical model to interpret the results. The study will utilize observations from ground-based instrumentation.

[3] The first high-latitude wind measurements that showed clearly the importance of electromagnetic forcing were published by Rees [1969] from data obtained by highaltitude sounding rockets. A number of similar measurements followed these early observations [Rees et al., 1998]. At lower latitude $\left(34^{\circ}\right)$, ground-based studies of neutral winds were also made by Armstrong [1969] during quiet solar and geomagnetic activity by observing the Doppler shifts of the neutral OI $630 \mathrm{~nm}$ emission line. First observations during a geomagnetic storm were obtained by Rees [1972] at high latitude, which again clearly showed the strong impact of ion drag on the high-latitude thermospheric wind system. Effects of geomagnetic activity were observed by Hays and Roble [1971] at midlatitude, which showed a meridional wind component reaching $400 \mathrm{~ms}^{-1}$. 
[4] Upper atmospheric winds in the northern polar cap were first measured by satellite accelerometer [DeVries, 1972; Wu et al., 1974]. During a geomagnetic storm wind velocities, at altitudes lower than $200 \mathrm{~km}$, reached several hundreds $\mathrm{ms}^{-1}$. For the first time a wind reversal was observed at auroral latitudes from the action of ion drag. The neutral winds in the northern polar cap were also studied using tracers composed of ionized and neutral barium and trimethyl aluminium trails injected in the thermosphere using sounding rockets [Meriwether et al., 1973]. Although these chemical releases lasted only a few hours, the series of rocket tracer experiments demonstrated variations in direction and amplitude of the wind velocity with geomagnetic activity. In quiet geomagnetic and solar activities, the thermospheric winds in the polar regions flowed from the dayside to the nightside in agreement with satellite measurements [King-Hele and Walker, 1983]. Observations in the evening and midnight sector are explained in term of ion drag forces. Long-duration observations in the polar cap region were carried out using interferometers based at College $\left(65^{\circ} 6^{\prime} \mathrm{N}, 147^{\circ} 30^{\prime} \mathrm{W}\right)$ [Hays et al., 1979] and at Svalbard $\left(78^{\circ} 12^{\prime} \mathrm{N}, 15^{\circ} 50^{\prime} \mathrm{E}\right)$ by Smith and Sweeney [1980]. These results confirmed the wind reversal in the evening sector of the auroral zone. Measurements above Svalbard, which covered all local time and $K_{p}$ values from 0 to $6^{-}$, have suggested that the movement of the neutral gas is mainly due to ion drag and that the energy is supplied from the magnetospheric electric field. Moreover, the westward direction of the winds on the dayside, which had been found for quiet geomagnetic conditions, would tend toward the antisolar direction when the geomagnetic activity increases, in response to an expansion of the polar cap.

[5] Simultaneous measurements of ion and neutral dynamics using radar and optical techniques were also used to understand ionosphere-thermosphere coupling [Nagy et al., 1974]. These measurements confirmed the complexity of the response of this medium during periods of elevated geomagnetic activity. A global view was obtained with two instruments carried on the Dynamic Explorer 2 spacecraft (DE2) placed in polar orbit: a Fabry-Pérot interferometer observing the meridional or in-track wind component and a mass spectrometer (WATS) [Spencer et al., 1981] measuring the zonal or cross-track component. These two instruments allowed observations of the thermosphere polar cap dynamics from August 1981 to February 1983. Data showed that thermospheric neutral winds respond first to momentum transfer between convecting ions and neutral gas, second, to the Joule heating of the neutral gas due to dissipation of energy which takes place during the momentum transfer, and third, to the direct precipitation of low-energy particles into the atmosphere [Hays et al., 1984]. DE2 data were used in the construction of the empirical Horizontal Wind Model (HWM) [Hedin et al., 1988; Hedin et al., 1991; Hedin et al., 1996]. Measurements carried out when the satellite crossed the northern magnetic pole showed very high velocity winds (up to $800 \mathrm{~ms}^{-1}$ ) flowing in the antisolar direction [Killeen et al., 1982]. The geomagnetic activity was weak $\left(A_{p}=9\right)$ but the solar activity was rather high (the solar flux at $10.7 \mathrm{~cm}$ reached 239). Nevertheless, the solar activity was not considered as having a direct influence on the dynamics of the thermosphere.
[6] Observations of vertical winds, as well as their source, have been the subject of extensive research. During the eighties, Aruliah et al. [1991] made long-duration observations of neutral winds at northern high latitude using a Fabry-Pérot interferometer. This instrument was not located in the polar cap region but in the auroral zone (Kiruna, $67^{\circ} 48^{\prime} \mathrm{N}, 20^{\circ} 24^{\prime} \mathrm{E}$ ). Measurements covered nearly a full solar cycle and allowed correlating of solar activity with the characteristics of the neutral winds. During weak geomagnetic activity $\left(K_{p}<2\right)$, no solar activity dependence of the thermospheric winds was observed. This has been interpreted as due to a poleward shrinking of the auroral oval from the site of the observations. In cases of high solar activity, the velocity of the neutral winds was observed to increase with geomagnetic activity. These observations also provided vertical wind component observations. The mean value of this component showed systematic variations, which depended on universal time, season, geomagnetic and solar activity, with values reaching $20 \mathrm{~ms}^{-1}$ [Aruliah and Rees, 1995]. The MICADO (Michelson Interferometer for Coordinated Doppler Observation) [Thuillier et al., 1990], installed at Sodankyla $\left(67^{\circ} 22^{\prime} \mathrm{N}, 26^{\circ} 38^{\prime} \mathrm{E}\right)$, has also been used to measure the three components of the neutral wind. In particular, the vertical wind component was found to be directly proportional to the change of the local horizontal magnetic field [Fauliot et al., 1993], the development of which was associated with heating of the thermosphere. The data from the WATS instrument on board DE-2 were used to derive vertical winds, which suggested gravity waves as the source [Innis and Conde, 2001, 2002]. Ishii et al. [2001] used two Fabry-Pérot interferometers to observe the green $(555.7 \mathrm{~nm})$ and red $(630 \mathrm{~nm})$ oxygen lines simultaneously. The data showed that vertical winds are associated with bright aurora features and that vertical winds measured by each line simultaneously were well correlated in most cases. In the absence of activity, vertical wind may exist resulting from the divergence of the horizontal wind system. During the Horizontal $E$ Region Experiment, vertical winds measured from two sites were found to be well correlated when the observations were within the same auroral arc [Ishii et al., 2003, 2004].

[7] Radar measurements, such as EISCAT, provide measurements of the ion velocity from which the meridional wind component can be derived. Comparisons with observed neutral winds have showed reasonable agreement especially during low geomagnetic activity [see, e.g., Lilensten and Lathuillère, 1995]. Discrepancies in the interpretation of horizontal winds can be due to vertical winds, which may reach several tens of $\mathrm{ms}^{-1}$ in case of high geomagnetic activity. Aruliah et al. [2004] have performed tristatic Fabry-Pérot observations colocated with the three EISCAT radars, allowing them to take into account the assumption of no vertical winds in the calculation of the meridional wind component from the ion velocity. These measurements allowed the role of the magnetospheric electric field and Joule heating in the thermosphere to be estimated. Observations above Svalbard may be found in the work of Aruliah and Griffin [2001], which showed an overestimate of HWM predictions with respect to observations for geomagnetically quiet conditions $(K p<2)$ at solar minimum. 
[8] On 10-11 January 1997, the effects of a CME were observed at Eureka $\left(80^{\circ} 6^{\prime} \mathrm{N}, 273^{\circ} 36 \mathrm{E}\right.$ and $88^{\circ} 54^{\prime}$ geomagnetic latitude). These observations showed the increase of the auroral lines emission rate due to particle precipitation [Steele et al., 1998].

[9] The last geophysical satellite mission performing wind observations was the Upper Atmosphere Research Satellite (UARS), on which two instruments were dedicated to wind measurements. However, few observations were made in the thermosphere and, with a spacecraft inclination $\left(57^{\circ}\right)$, despite viewing at 45 and $135^{\circ}$ with respect to the velocity vector, the polar cap was rarely observed.

[10] This review of available high-latitude wind observations clearly shows that although many observations have been made, those in the polar cap are scarce. The scarcity of data provides the motivation for the present Svalbard observation program.

\subsection{Wind Models}

[11] The previous wind measurements have been used in a number of models. The Horizontal Wind Model (HWM) is an empirical model of the horizontal wind components of the neutral atmosphere. It was first based on thermospheric wind data delivered by the Atmosphere Explorer E and Dynamics Explorer 2 satellites. Consequently, the first version (HWM87) was limited to altitudes higher than $200 \mathrm{~km}$ [Hedin et al., 1988] and had no solar cycle dependence. Later, inclusions of wind data from ground measurements permitted the altitude regime to be extended down to $100 \mathrm{~km}$ (HWM90) [Hedin et al., 1991] and finally to the ground (HWM93) [Hedin et al., 1996]. These data and gradients of the winds derived from density and temperature models allow HWM93 to take into account daily and semiannual variations; it also includes variations with longitude as well as solar and magnetic activity. Moreover, some data from ground-based observations at high northern latitudes were used, including some collected at Svalbard when the solar activity was moderate or high, i.e., for a $10.7 \mathrm{~cm}$ solar flux between 120 and 270 units. Consequently, the model should be reasonably well adapted to simulate the wind at Svalbard in the case of high geomagnetic disturbances such as encountered during the 28 October 2004 coronal mass ejection.

[12] However, the relative weight of the specific Svalbard data with respect to measurements at lower latitudes is low. The representation of the model in vector spherical harmonics leads to averaging of localized measurements of high wind velocities and rapid spatial and temporal gradients. Moreover these data are not uniformly distributed with altitude: in the $130-250 \mathrm{~km}$ altitude range, spacebased data for the zonal component only exist in the equatorial region, while in the $90-130 \mathrm{~km}$ region the zonal variations are underestimated. Ground-based FabryPérot measurements can generally only be obtained during the night period and have been introduced in the HWM model via the assumption that the vertical wind component is zero.

\subsection{Physical Models}

[13] In order to understand and help to interpret the observed neutral wind response to geomagnetic activity, the present results are compared with numerical simulations using a coupled thermosphere-ionosphere-plasmasphereelectrodynamic (CTIPe) physical model. CTIPe is a global, three-dimensional, time-dependent, nonlinear model that is a union of four physical components. The first is a global, nonlinear, time-dependent neutral thermospheric code developed by Fuller-Rowell and Rees [1980, 1983]. The second is a midlatitude and high-latitude ionospheric convection model developed by Quegan et al. [1982]. These first two components were initially coupled selfconsistently and are known as the Coupled ThermosphereIonosphere Model (CTIM) [Fuller-Rowell et al., 1996a]. CTIM was further extended by including a third component, a plasmasphere and low-latitude ionosphere [Millward et al., 1996], to produce CTIP. Finally, the electrodynamics was included self-consistently for the midlatitude and lowlatitude electric field using the code of Richmond and Roble [1987]. The model is time-dependent, creating a global distribution of all the major parameters every minute, suitable for studies of any region of the globe.

[14] CTIM and CTIPe have been used extensively to investigate and understand the response of the thermosphere and ionosphere to geomagnetic storms [Fuller-Rowell et al., 1994, 1996a]. For the present study, the magnetospheric convection electric field and the auroral precipitation are described by the empirical models of Weimer [1996] and Fuller-Rowell and Evans [1987], respectively. The Weimer patterns are driven by the time history of the solar wind interplanetary magnetic field and velocity as measured by the ACE spacecraft. The auroral precipitation patterns are driven by the auroral power index from the TIROS/NOAA series of satellites.

\subsection{EPIS Investigation Objectives}

[15] The EPIS investigation (Etude Polaire par Interfermétrie à Svalbard) is dedicated to the study of the dynamics of the thermosphere and lower thermosphere in the polar cap. In this region, the solar particles may directly interact with the upper atmosphere by generating ions, heating the species, and producing aurora. In addition, the momentum source from ion convection modifies the wind regime. As we saw in the previous section, observations in the region are scarce compared to the auroral zone and lower latitudes. Consequently, modeling of the dynamics in this region suffers from a lack of data.

[16] Our aim is to measure the three components of the wind as a function of solar activity, determine their relationship with aurora and geomagnetic activity, and quantify the ion drag effects on the thermosphere dynamics. The instrument is presently installed at the station in Longyearbyen, close to the EISCAT Svalbard Radar (ESR) with which we plan to operate. This active instrument measures the temperature of the ions and electrons, the electron density, and the ion velocity. This investigation follows a campaign performed in the 1990s with the MICADO interferometer installed at Sodankyla (Finland) and operated in conjunction with the EISCAT radar.

\subsection{Coronal Mass Ejection of 28 October 2003}

[17] Near the end of October 2003, three solar active regions generated Earth-directed CMEs and intense flares 


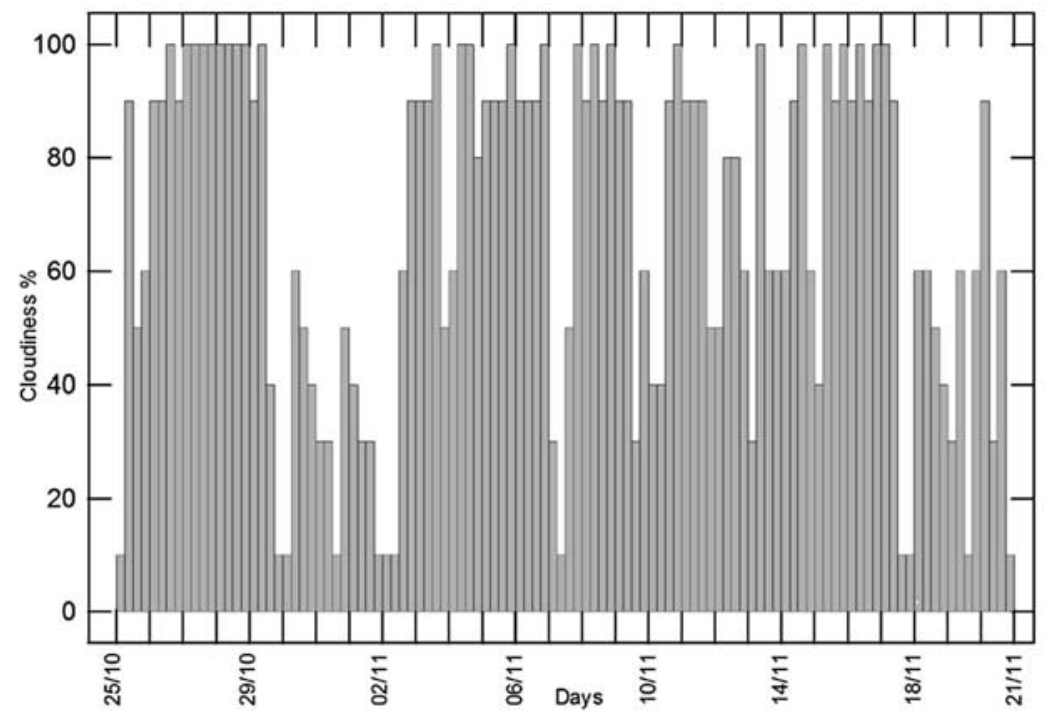

Figure 1. The local meteorological conditions at Svalbard from 25 October to 21 November 2003.

containing solar energetic particles. Owing to the direction of their ejection, the CMEs interacted with the terrestrial magnetosphere and ultimately with the Earth's upper atmosphere. On 28 October at 0951, the Sun unleashed a CME, which was related to a X17.2 flare. In terms of magnitude, this was the third largest flare measured since 1980. Owing to the travel time for the CME to reach the Earth, the terrestrial magnetic field was significantly perturbed on 29 October between 0600 and 0900 UT. The $K p$ index reached 9 during this period, while the Svalbard local index $K_{L}$ reached 8 in the subsequent 3-hour slot. The impact of this $\mathrm{CME}$ on the terrestrial magnetosphere generated a huge geomagnetic storm, which greatly disturbed the Earth's thermosphere at all latitudes. The dynamic response at high latitudes to a similar unusual CME event in February 1982 was reported by Rees [1993]. Most of the ground-based observations were carried out in the Northern Hemisphere; however, the geomagnetic storm of 11-13 June 1991 has been observed in the Southern Hemisphere from two stations, Mt John (New Zealand, $44^{\circ} \mathrm{S}, 171^{\circ} \mathrm{E}$ ) and South Pole as reported by Smith et al. [1994]. The wind velocity and temperature were observed to reach $800 \mathrm{~m} / \mathrm{s}$ and $2000 \mathrm{~K}$, respectively, at the pole, while the wind velocity was only peaking at $300 \mathrm{~m} / \mathrm{s}$ at midlatitudes, suggesting the role of the sign of the interplanetary magnetic field $Y$ component for understanding these differences.

\subsection{Objectives of the Present Article}

[18] The transparency of the lower atmosphere has been up to now a serious obstacle to our objectives. However, acceptable observing conditions did occur during the coronal mass ejection of 28 October 2003. As may be seen in Figure 1, cloudiness decreased by 1200 UT on the next day, allowing observations of the effects on the dynamics of this extreme solar event. This article is dedicated to describe the wind variations during this event and comparing with the predictions of the Hedin [1996] empirical model, the CTIPe physical model, and derived wind from the ESR measurements.

\section{Instrument and Campaign 2003-2004 \\ 2.1. Instrument EPIS}

\subsubsection{General Concept}

[19] The Doppler shift between an emitting species in motion and at rest provides the velocity along the line of sight. A Michelson interferometer is an appropriate instrument for these purposes. However, the narrow field of view of the conventional Michelson interferometer results in a weak signal. A modification by Bouchareine and Connes [1963] allowed enlarging the accepted instrument solid angle and, consequently, the signal to noise ratio. However, the modified instrument uses a block of glass for compensating the effect of the inclination of the off-axis rays and becomes sensitive to variations of temperature. By choosing material of appropriate refractive index, thermal expansion coefficient, and dimension for the glass, a temperature compensation of the instrument optical path is achievable. This concept was used for our previous instrument (MICADO, Michelson Interferometer for Coordinated Auroral Doppler Observations) [Thuillier and Hersé, 1991].

[20] The signal $I(x)$ generated given by the interferometer is described by:

$$
I(x)=I_{0}\left(1+U_{\lambda} V \cos \left(2 \pi(\Delta+x) / \lambda+\varphi_{0}\right)\right)+I_{B},
$$

where $x$ is the optical path difference change. The optical path difference is incremented step by step from zero to a step number $(\delta)$ corresponding to an integer number of wavelengths. Here $\lambda$ is the line wavelength; $U_{\lambda}$ is the line visibility related to its temperature; $V$ is the instrument visibility; $\Delta$ is the optical path difference; $I_{0}$ and $I_{B}$ are the line intensity and the line background, respectively. 
The later is independently measured. By recording an integer number of fringes, we calculate:

$$
\begin{gathered}
S_{1}=1 / n \int_{0}^{\delta} I(x) d x \\
S_{2}=-2 / n \int_{0}^{\delta} I(x) \cos \varpi x d x \\
S_{3}=-2 / n \int_{0}^{\delta} I(x) \sin \varpi x d x,
\end{gathered}
$$

where $\varpi$ is $2 \pi \Delta / \lambda$, and $\delta$ is the total optical path difference variation, $\lambda_{0}$ is the wavelength at rest, and $n$ is the total number of measurements for scanning $\mathrm{m}$ fringes. Equation (1) being introduced in equations (2), (3), and (4), we obtain:

$$
\begin{gathered}
S_{1}=I_{0}+I_{B} \\
S_{2}=I_{0} U_{\lambda} V \cos \left(\varphi+\varphi_{0}\right) \\
S_{3}=I_{0} U_{\lambda} V \sin \left(\varphi+\varphi_{0}\right)
\end{gathered}
$$

The above three sums are calculated from the data. Here $\varphi_{0}$ is the zero wind phase, and $\varphi$ is the phase variation induced by the wind, which provides the velocity along the line of sight. Knowing $I_{B}, \varphi_{0}, I_{0}, \varphi$ can be extracted; the latter provides the wind velocity from

$$
v=K \varphi
$$

where $K$ is calculated from the mediums (air, glasses) characteristics (thickness and refraction index) used for the interferometer. By observing in three directions, it is possible to derive the vertical, meridional, and zonal wind components.

\subsubsection{Instrument}

[21] The line to analyze is selected by interference filters installed on a filter wheel. These filters have a narrow spectral bandwidth (about $1 \mathrm{~nm}$ ) for reducing the background line intensity effect which decreases the signal modulation. The variation of the optical path difference is provided by moving an optical wedge perpendicularly to the optical axis. The precise position of the wedge is monitored by generating an interferogram using a stabilized laser $\left(3 \times 10^{-9}\right.$ stability). Periodically, the instrument is calibrated in intensity (relative scale) by using a tungsten ribbon lamp. Visibility is calibrated by using a laser, where the beam is spread over the optical entrance pupil, and the phase is calibrated by using spectral lamps providing emission lines as close as possible to the selected emission lines. The background intensity is measured by taking a part of the light entering the Michelson through an interference filter having a bandwidth close to the airglow line. Similarly, the line intensity is independently measured in order to follow rapid variations of the line intensity as encountered at high latitude and to correct the interferogram.

[22] The interferometer, light collector, various optical devices for calibration, associated electronics, and thermal regulation are housed in a container. Its roof is topped with a truncated pyramid, where a plane mirror, which is movable in elevation and in azimuth, allows pointing between 20 and 60 degrees above the horizon. A $150 \mathrm{~cm}$ focal length and $15 \mathrm{~cm}$ aperture lens collects light on the entrance pupil. By setting the scanning mirror in the vertical plain, zenith observations can be obtained. The field of view is two arc degrees (Figure 2).

[23] The instrument has four channels of measurements: (1) measurement of the wedge position using the laser beam, (2) measurement of the interferogram corresponding to the selected airglow line, (3) measurements of the line intensity by use of the beam splitter, and (4) measurement of the line background using reflected light on the filter which selects the line intensity.

[24] The airglow and the calibration lines are presently:

$$
\begin{aligned}
& \mathrm{OI}(557.7 \mathrm{~nm}) \text { with } \mathrm{Kr}(557.0 \mathrm{~nm}) \\
& \mathrm{OI}(630 \mathrm{~nm}) \text { with } \mathrm{Ne}(630.4 \mathrm{~nm})
\end{aligned}
$$

A tungsten ribbon lamp provides a relative photometric reference of airglow line intensity and allows measurement of the responsivity ratio of the photometric channels.

\subsection{Data Processing}

[25] The interferogram measurement provides $S_{1}, S_{2}, S_{3}$ (see equations (5), (6), and (7)). Equations (6) and (7) are combined to derive the phase $\left(\varphi+\varphi_{0}\right)$, and knowing the zero wind phase $\left(\varphi_{0}\right)$, the wind velocity is obtained from equation (8). An aurora is a variable intensity source, which results in the interferogram having a variable amplitude, as can be shown from equation (1). As the line intensity is measured separately, data from the interferometer channel can be normalized with the line intensity measured at the same time by the photometric channel. An example of the correction is shown on Figure 3.

[26] The zero wind phase $\left(\varphi_{0}\right)$ may be determined by several ways: (1) by observing at zenith and assuming a null vertical wind. This hypothesis is at best applicable in absence of geomagnetic activity, (2) by setting to zero its mean over the night, or (3) by using the scattering of photons from different directions providing a cancellation of the resulting Doppler effect. None of these hypotheses is straightforward to apply whichever way the zero wind phase is calculated. There is also a basic assumption in wind determination, which is homogeneity of the atmosphere above the instrument. For the red line oxygen layer and for a $30^{\circ}$ elevation, the observed area is located at $450 \mathrm{~km}$ from the zenith observations.

\subsection{Observations During the 2003-2004 Campaign}

[27] The instrument was installed at Svalbard in October 2002 after having run in test mode at Observatoire de Haute Provence (OHP), where it was built. The instrument was operated remotely from OHP with quick-look analysis but without local maintenance. Given some technical problems and weather conditions, few usable data were obtained before the October 2003 storm 


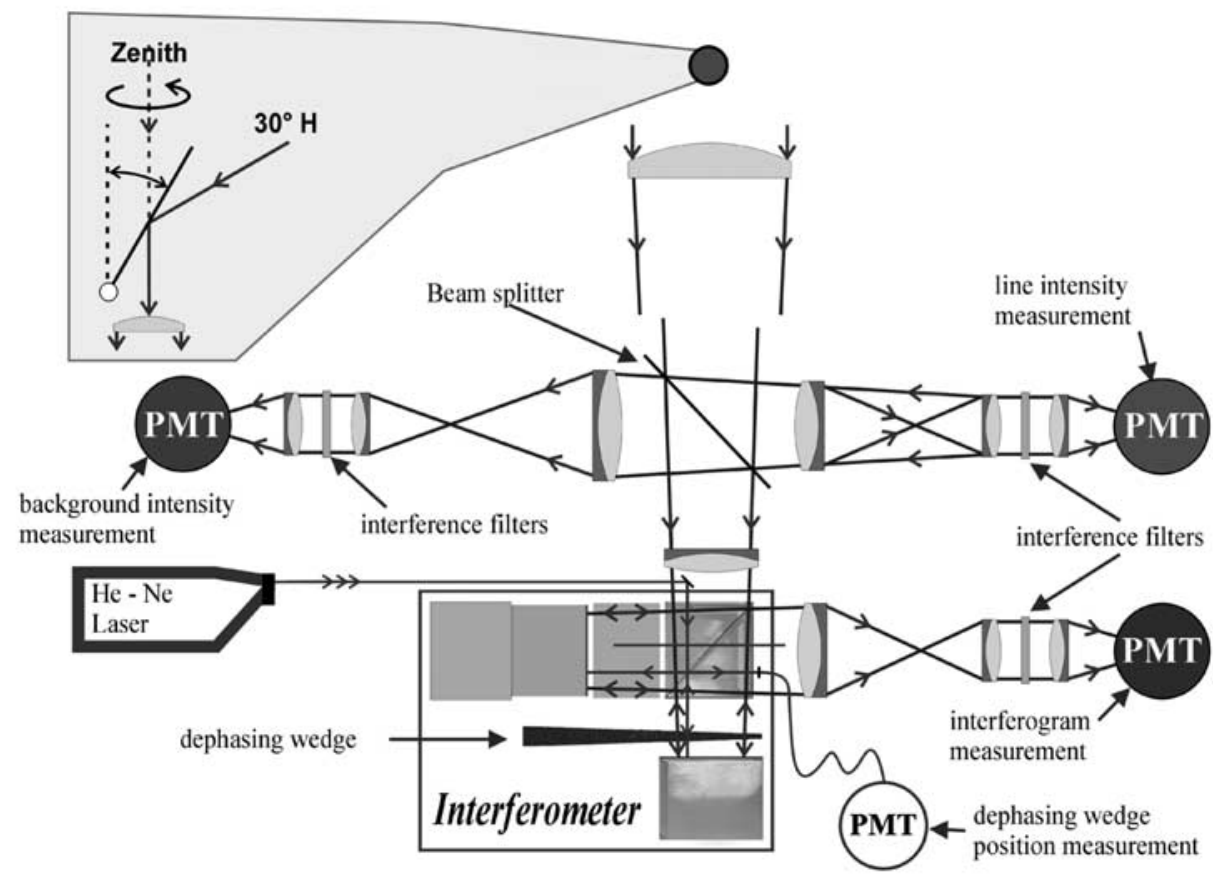

Figure 2. The optical Michelson interferometer schematics. The beam splitter allows generating the interferogram together with the measurement of the line intensity. As the light rejected by the line intensity filter is reflected back, the line background is measured at the same time.

[28] As local meteorological conditions are generally poor, the instrument is run when the outside temperature is below $-10^{\circ} \mathrm{C}$ to increase the chances of observations in acceptable conditions. Figure 1 shows the lower atmosphere transparency index from 25 October to 20 November 2003. A slot of acceptable weather condition was obtained from 30 October to 1 November. At this point, it is important to discuss the effect of cloudiness on interferometric measurements:
[29] First, nebulosity decreases the signal amplitude that is received. However, for wind measurements, photons from different directions may mix, leading to a decrease in the wind information from their Doppler shift. We have verified in cloudy conditions that by observing in two opposite directions, the interferogram phases are nearly equal, which produce no net Doppler shift. Consequently, cloudy conditions lead to a decrease in the wind velocity. This suggests that the phase for a null wind can be

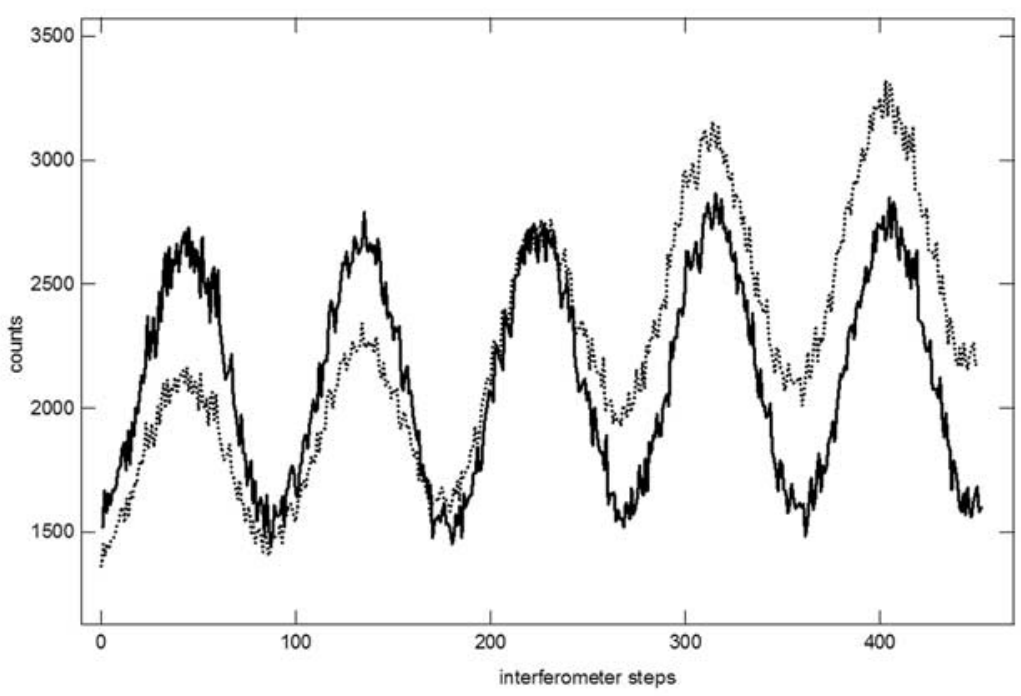

Figure 3. Processing of the interferometer data recorded with a source of variable intensity (dash line). The uncorrected fringes are shown. They are corrected by use of the photometric channel making constant the fringes amplitude (solid line). 

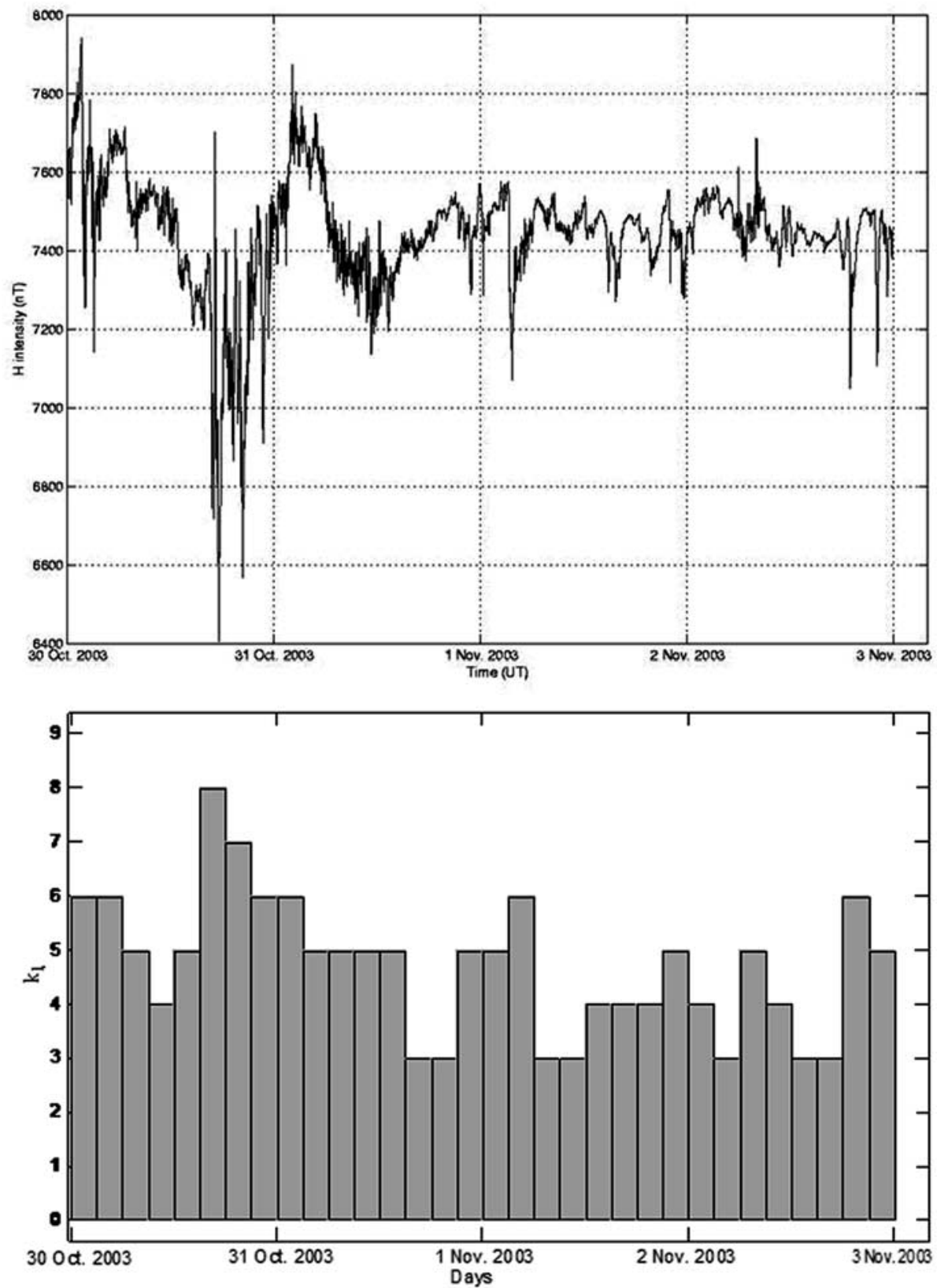

Figure 4. Geomagnetic activity from 30 October to 2 November 2003 over Svalbard described by the horizontal magnetic field component (upper panel) and the 3-hour local $K_{L}$ index (lower panel).

obtained in this way. This method was applied to the MICADO data for deriving vertical winds during clear atmosphere conditions. A difficulty arises when observing conditions are acceptable but not perfect, i.e., when photons are partially scattered. These were the conditions for the current observations reported here, so the data presented in this article do not take into account vertical wind. This factor may change the horizontal component by a maximum of $50 \mathrm{~ms}^{-1}$ and cloudiness could also decrease the measured wind.

[30] For monitoring cloudiness, indices of lower atmosphere transparency are used, provided every 6 hours by the Longyearbyen airport located $6 \mathrm{~km}$ from our observation site. This cloudiness index (CI) varies from 0 to unity $(0$ is for no cloudiness). We also detect cloudiness in our data by calculating the interferogram visibility, which typically decreases to 0.4 for a CI equal to 0.3 . Data presented below are with CI usually between 0.4 and 0.2 , at best 0.1 , and never 0 .

[31] In the following sections, we shall compare our ground-based measurements with models predictions. As we are observing from ground, an integration of the emission line intensity is performed along the line of sight. Consequently, the wind information is weighted by the vertical distribution of the line emission rate. In cases where the wind distribution consists of a homogenous layer, there 


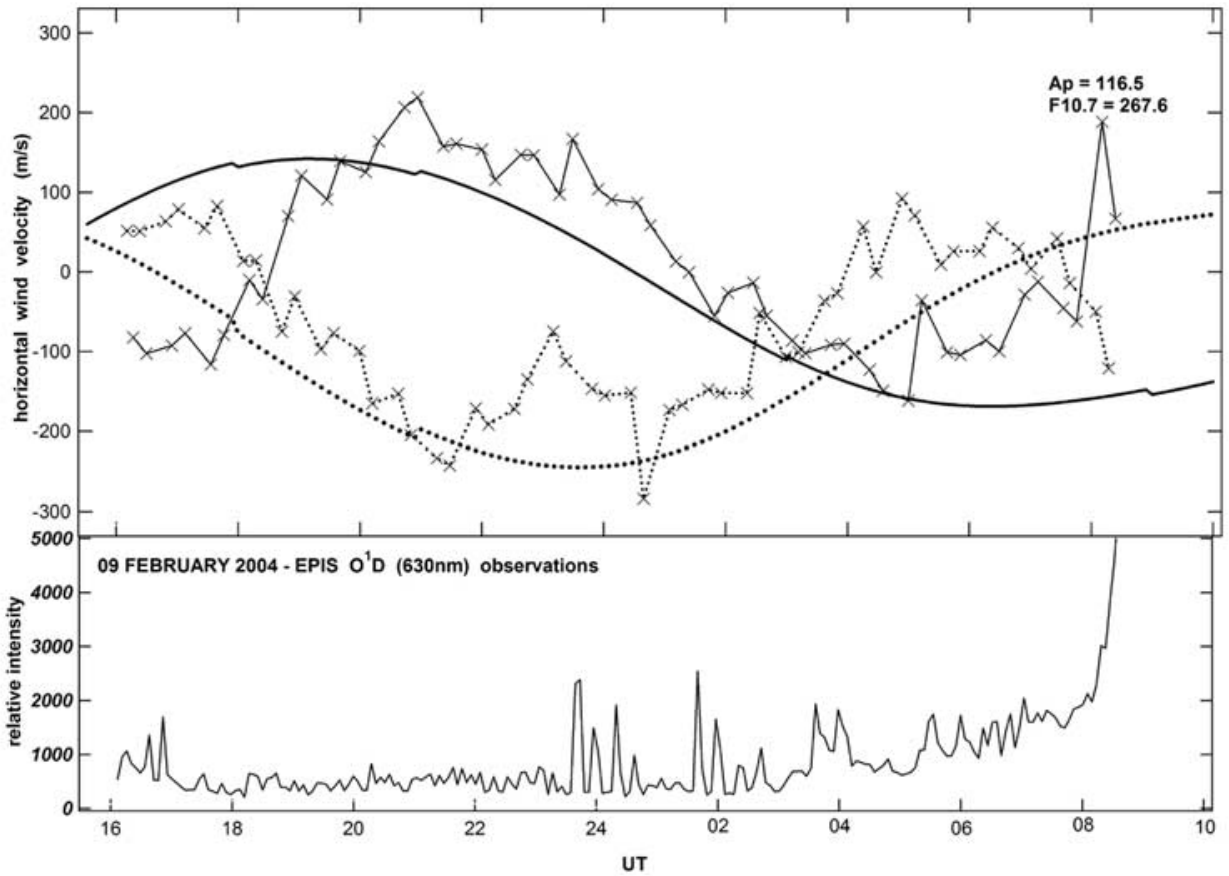

Figure 5. Wind and zenith line intensity (lower panel) measurements for the night of 9 February 2004. Measured winds are displayed with crosses (solid line is the zonal component, dash line is the meridional wind). $K_{1}$ reaches a maximum value of 3 during the observations. HWM model predictions are displayed (solid line is the zonal component, dash line is the meridional component).

is no ambiguity. For the disturbed cases, the comparison with models may be not straightforward.

\section{Results}

\subsection{Results Obtained Under Conditions of Low Geomagnetic Activity}

[32] Data collected on 9 February 2004 were in acceptable weather conditions and are shown in Figure 5. Solar activity given in terms of $F 10.7$ units and magnetic activity in terms of $A p$ index were 113 and 6.6, respectively. Using these values, HWM predictions were also calculated and are depicted on the same figure. Given that some clouds may have occurred, it appears that HWM correctly predicts the two wind components above Svalbard for the conditions encountered.

\subsection{Observations After the 28 October 2003 Event}

[33] The first observations during the Halloween storm started on 29 October. The weather conditions became acceptable for interferometer measurements by $2100 \mathrm{UT}$ on 30 October (the data are displayed on Figure 6 from 1600 UT). Wind amplitude shows significant changes either due to temporary cloudy periods, amplitude variation associated with geomagnetic activity, or from the influence of vertical winds. The latter effect could be of the order of $50 \mathrm{~ms}^{-1}$, which is smaller than the observed fluctuations. Figure 6 suggests that the zonal component appears more disturbed than the meridional one. The peaks in velocity of the zonal component at 2230 and 2330 correlate with a sharp decrease of the horizontal magnetic field component. Furthermore, at 2330, a peak in zenith intensity (reaching 4000 relative units) is likely due to particles precipitation. However, this is not observed at 2230 UT. On 31 October (Figure 7), before 2200 UT, the airglow intensity significantly decreased (in agreement with $K_{L}$ ), while the cloudiness remains low. We note the large increase in the zonal component with respect to the HWM prediction. After $2200 \mathrm{UT}$, a perturbation occurs which produces an increase of intensity, at the same time as the wind departs from the HWM prediction. On 1 November (Figure 8), before 1600 UT, $K_{L}$ increased to 6 , then decreased, and rose again after 2200 UT. The response to the geomagnetic activity is apparent in the meridional component. However, the zonal component remains above the HWM predictions all through the night.

\subsection{Comparison With ESR Derived Neutral Winds}

[34] The ion velocity measured by the ESR radar, given its high coupling with the neutral species, may be used to derive the meridional neutral wind velocity. Some assumptions are necessary including steady state conditions and no vertical winds. This method has been extensively used to provide the thermospheric meridional wind at middle and high latitudes [Buonsanto and Witasse, 1999; Witasse et al., 1998]. In the auroral zone, the MICADO interferometer data [Thuillier et al., 1990; Lilensten et al., 1992] or the WINDII interferometer observations [Lathuillère et al., 1997] showed that vertical winds should not be neglected. However, these vertical winds are expected to vary with small spatial and timescales, allowing derivation of the meridional winds.

[35] Neutral winds are estimated from the ESR data at 1-hour resolution and are shown in Figure 9. The calculated and observed neutral winds are in agreement in terms 


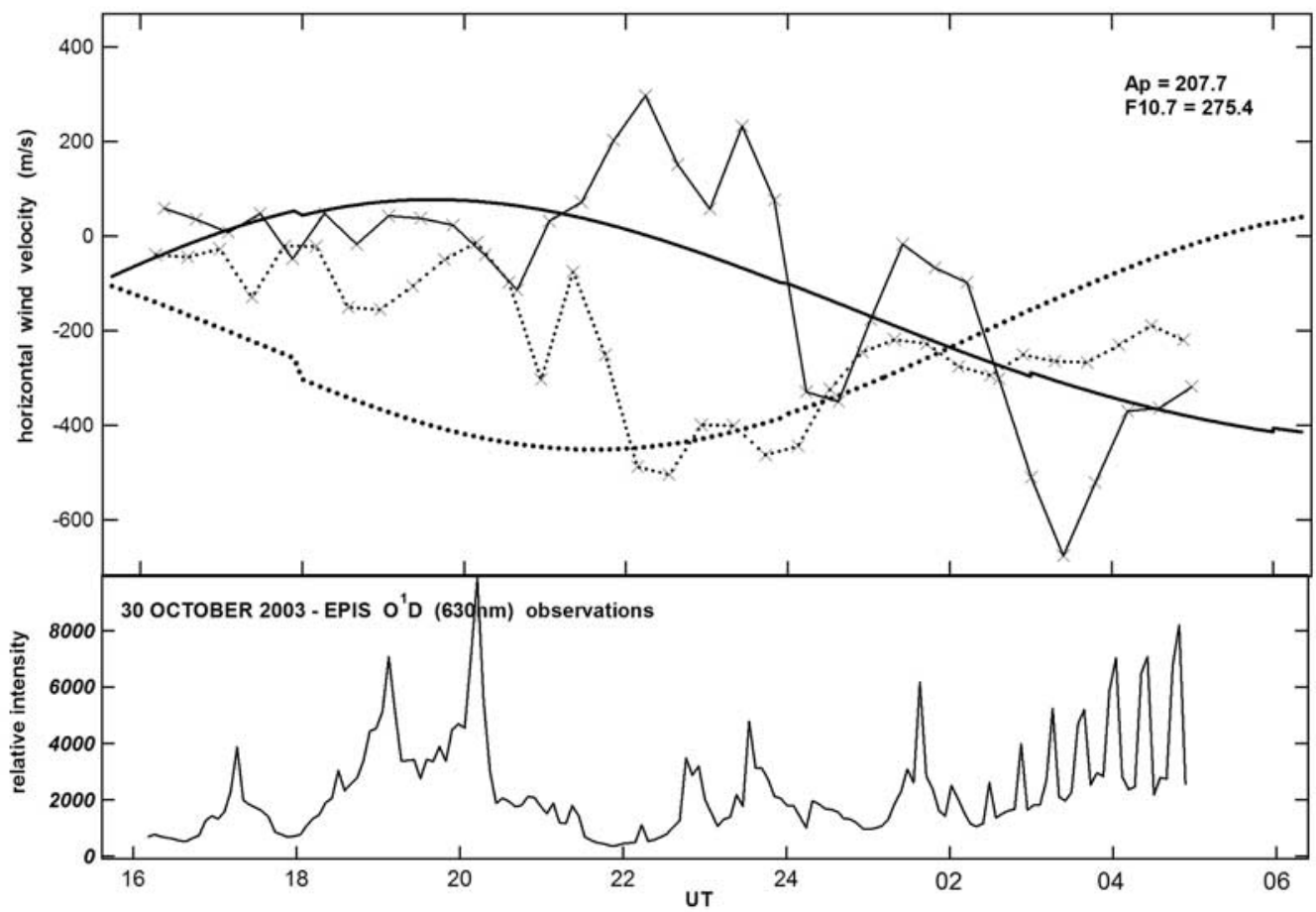

Figure 6. Wind and zenith line intensity (lower panel) measurements for the night of 30 October 2003. Measured winds are displayed with crosses (solid line is the zonal component, dash line is the meridional wind). Conditions of observations became acceptable by 2100 UT. $K_{1}$ reaches a maximum value of 8 during the observations. HWM model predictions are displayed (solid line is the zonal component; dashed line is the meridional component).

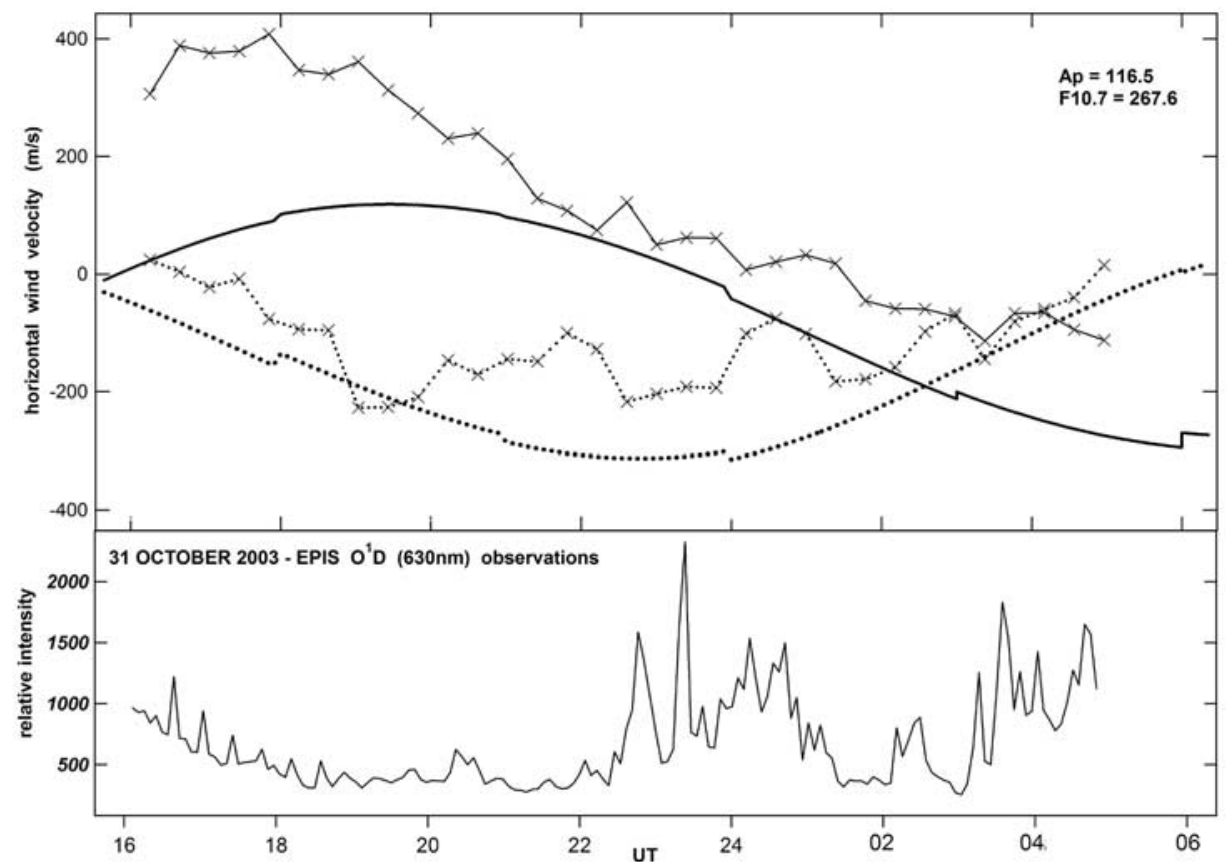

Figure 7. Wind and zenith line intensity (lower panel) measurements for the night of 31 October 2003. Measured winds are displayed with crosses (solid line is the zonal component, dash line is the meridional wind). $K_{1}$ reaches a maximum value of 6 during the observations. HWM model predictions are displayed (solid line is the zonal component, dash line is the meridional component). 


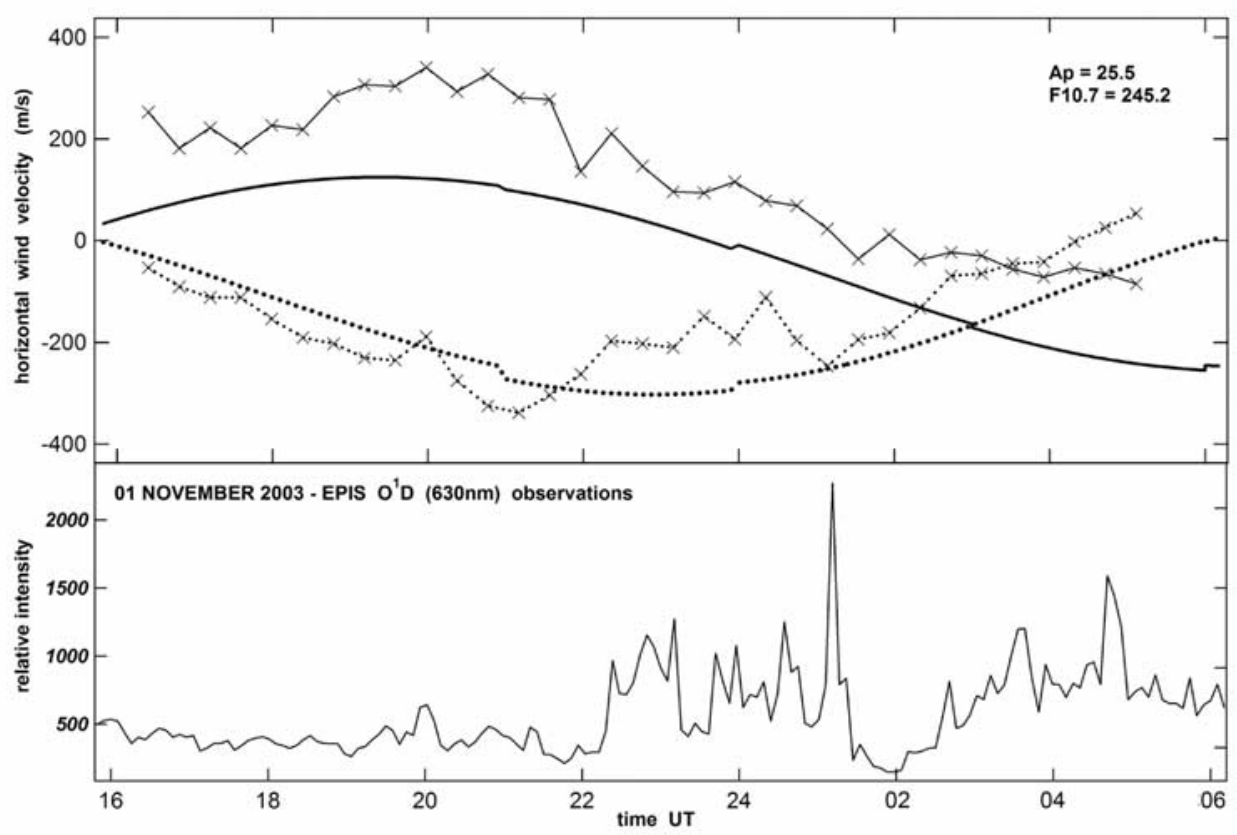

Figure 8. Wind and zenith line intensity (lower panel) measurements for the night of 1 November 2003. Measured winds are displayed with crosses (solid line is the zonal component, dash line is the meridional wind). $K_{1}$ reaches a maximum value of 6 during the observations. HWM model predictions are displayed (solid line is the zonal component, dash line is the meridional component).

of magnitude and their change with time. In particular, the equatoward increase of the wind velocity during the night on 29 to 30 October can be related, without ambiguity, to the magnetic activity induced by the 29 October CME.

[36] This figure also displays the HWM model predictions, which predicts smooth changes partly due to the use of the 3-hour geomagnetic index. This introduces a strong time filtering and consequently does not take into account the highly disturbed and rapidly changing conditions existing at that time.

\subsection{Comparison With CTIPe Neutral Wind}

[37] The October period of observations was also simulated by the CTIPe physical model and the values of zonal and meridional wind predicted by the model were extracted. Figure 10 shows comparison with the Svalbard wind

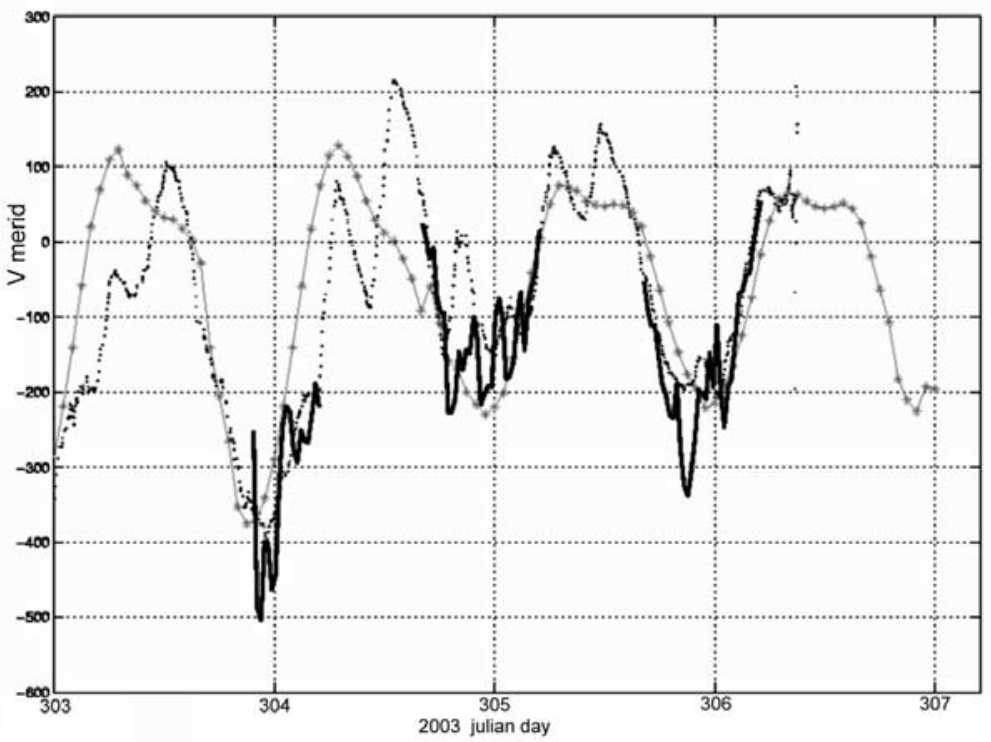

Figure 9. Comparison between the meridional wind component observed by EPIS (thick solid line) and the calculated meridional wind from the ion velocity measured the ESR radar (dash line). The HWM predictions (line and dots) are also shown. 

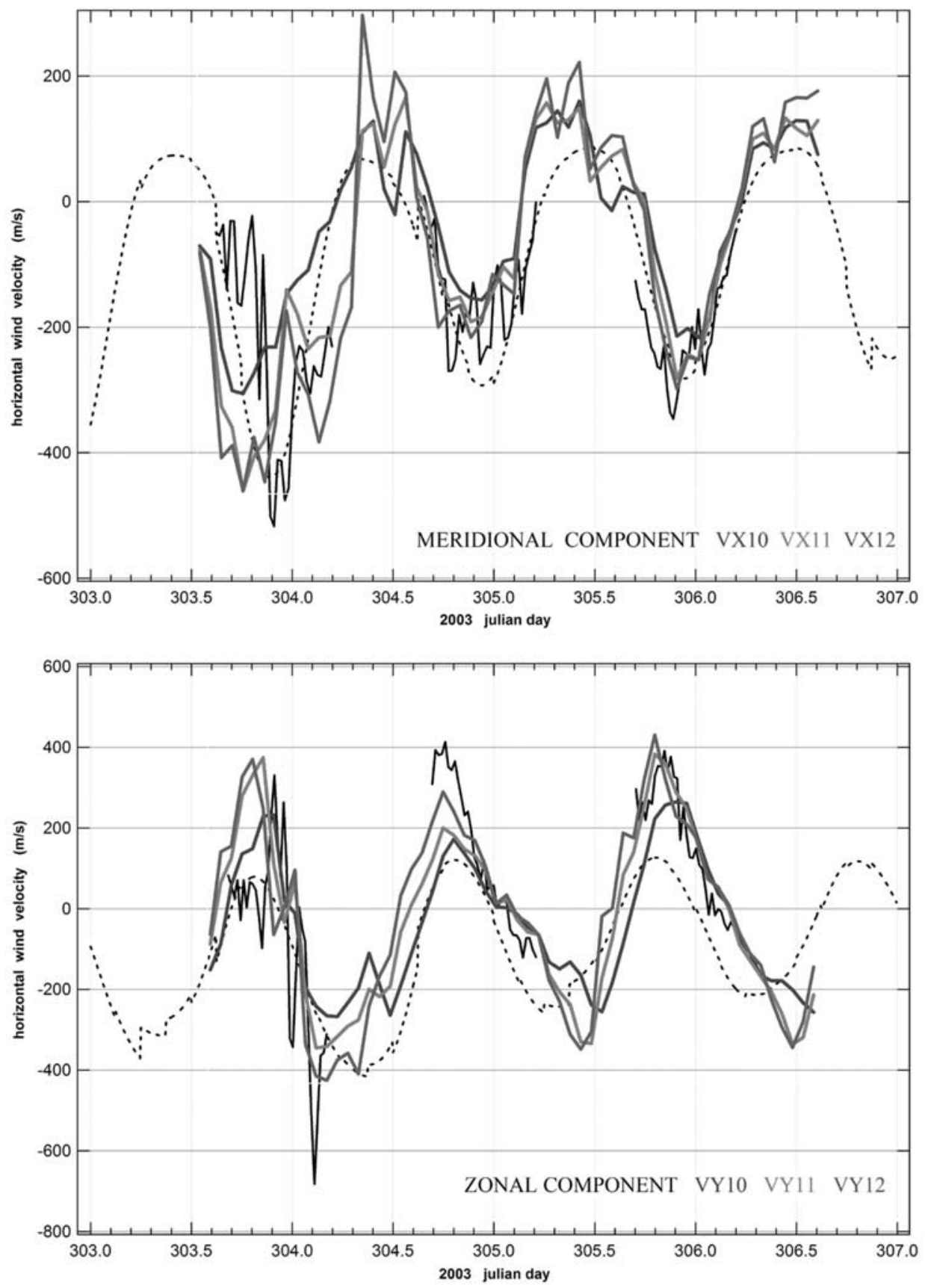

Figure 10. Comparison between the wind observed by EPIS (black solid line), the HWM model (dashed line), and the calculated wind (solid lines in color) using the CTIPe model. The velocity is calculated at three levels denoted VX10, VX11, VX12 for the meridional component (upper panel), and VY10, VY11, VY12 for the zonal component (lower panel). See color version of this figure at back of this issue.

observations. Three altitude levels were selected from the model covering the expected range of heights for the airglow emission. Under normal conditions the peak in the airglow is expected to be below the $F$ region electron density peak, at around $240 \mathrm{~km}$ altitude. This level corresponds roughly to the level 11 winds from CTIPe shown in Figure 10. Heating at high latitudes due to the magnetospheric activity will tend in increase the altitude of the emission layer. Since CTIPe uses a pressure coordinate system, the levels in the model will rise and fall with the heating. The uncertainty in the emission height can also be influenced by the local auroral conditions. The alternative levels from the model, level 10 and 12 , are approximately $40 \mathrm{~km}$ below and above level 11 , respectively, and are expected to cover the range of uncertainty in the emission heights.

[38] Generally, the winds at CTIPe level 12 tend to agree most favorably with the Svalbard observations. The results from the physical model tend to show much more variability than the HWM as well as greater amplitude. Figure 10a shows a comparison of the meridional wind component. 
Note that before 2100 UT on 30 October the observed winds are not reliable due to poor observing conditions. On this first day the magnitudes of the winds are in reasonable agreement with the observations, although the timing of some of the wind surges and rapid fluctuations are not always well represented by the model. The agreement in magnitude and phase is substantially better on the second and third days.

[39] Figure 10b shows a comparison of the zonal wind component. After 2100 UT, when the observations are reliable, the general shape and timing of the wind increase appears reasonable, but the model does not reproduce the short-lived spikes in the wind observations. On the second day, again the shape is in reasonable agreement but the amplitude from the simulation is a little low. For the third day, the agreement is reasonably good in terms of phase and amplitude. Generally, given the highly variable condition, the agreement between the model and data, although not perfect, is very encouraging. In particular, the simulations tend to show the variability from day-to-day, in response to the rapidly changing magnetospheric convection and the impact of ion drag. In addition, the model reproduces the magnitude of the observations with reasonable fidelity.

\section{Conclusion}

[40] The effects of the CME of 28 October 2003 on the polar thermosphere neutral wind field were observed during 3 days of acceptable meteorological conditions above Svalbard. Observations were carried out by the EPIS interferometer. Comparison with the HWM model shows a better agreement for the meridional component than for the zonal component. The meridional component derived from ESR data shows agreement with observations, despite the significantly perturbated thermosphere by energetic particles precipitation, and strong convective electric fields. Comparisons with GCM predictions show good agreement for the horizontal wind components, and in particular, was slightly better for the meridional than the zonal component. The intensity of the $\mathrm{O}^{1} \mathrm{D}$ line emission was greater by a factor of 8 compared with values typical of quiet geomagnetic conditions. Meteorological conditions during this campaign were generally poor and were a strong limitation to further investigations of the differences between observations and predictions during this period of highly disturbed geomagnetic conditions.

[41] Acknowledgments. The EPIS instrument has been funded by INSU through the PNST program. We thank the University of Svalbard for providing the facilities of the auroral station where EPIS is installed. The ESR facility is supported by the research council of Finland (SA), France (CNRS), the Federal Republic of Germany (MPG), Norway (NAVF), Sweden (NFR), and the United Kingdom (PPARC). Geomagnetic data were provided by the Tromso Geophysical Observatory. We thank J. P. Sivan, formally Director of the Observatoire de Haute Provence for his support, as well as the technical staff for building the instrument. We thank the referee for his valuable suggestions and encouragements.

[42] Arthur Richmond thanks the reviewer for his assistance in evaluating this paper.

\section{References}

Armstrong, E. B. (1969), Doppler shift in the wavelength of the OI $\lambda 6300$ line in the night airglow, Planet. Space Sci., 17, 957-974.

Aruliah, A. L., and E. Griffin (2001), Evidence of meso-scale structure in the high-latitude thermosphere, Ann. Geophys., 19, 37-46.
Aruliah, A. L., and D. Rees (1995), The trouble with thermospheric vertical winds: Geomagnetic, seasonal and solar cycle dependence at high latitudes, J. Atmos. Terr. Phys., 57, 597-609.

Aruliah, A. L., D. Rees, and T. J. Fuller-Rowell (1991), The combined effect of solar and geomagnetic activity on high latitude thermospheric neutral winds. part I. Observations, J. Atmos. Terr. Phys., 53, 467-483.

Aruliah, A. L., E. M. Griffin, I. McWhirter, A. D. Aylward, E. A. K. Ford, A. Charalambous, M. J. Kosh, C. J. Davis, and V. S. C. Howells (2004), First tristatic studies of mesoscale ion-neutral dynamics and energetics in the high-latitude upper atmosphere using colocated FPIs and EISCAT radars, Geophys. Res. Lett., 31, L03802, doi:10.1029/2003GL018469.

Bouchareine, P., and P. Connes (1963), Interféromètre à champ compensé pour spectroscopie par transformation de Fourier, J. Phys., 24, 134-138.

Buonsanto, M. J., and O. Witasse (1999), An updated climatology of thermospheric neutral winds and $F$ region ion drifts above Millstone Hill, J. Geophys. Res., 104, 24,675-24,687.

DeVries, L. L. (1972), Structure and motion of the thermosphere shown by density data from Low-G Accelerometer Calibration System (LOGACS), Space Res., 12, 867-879.

Fauliot, V., G. Thuillier, and M. Hersé (1993), Observations of the F-region horizontal and vertical winds in the auroral zone, Ann. Geophys., 11, 1728.

Fuller-Rowell, T. J., and D. S. Evans (1987), Height-integrated Pedersen and Hall conductivity patterns inferred from the TIROS/NOAA satellite data, J. Geophys. Res., 92, 7606-7618.

Fuller-Rowell, T. J., and D. Rees (1980), A three-dimensional, time-dependent, global model of the thermosphere, J. Atmos. Sci., 37, 2545.

Fuller-Rowell, T. J., and D. Rees (1983), Derivation of a conservation equation for mean molecular weight for a two constituent gas within a three-dimensional, time-dependent model of the thermosphere, Planet. Space Sci., 31, 1209.

Fuller-Rowell, T. J., M. V. Codrescu, R. J. Moffett, and S. Quegan (1994), Response of the thermosphere and ionosphere to geomagnetic storms, J. Geophys. Res., 99, 3893-3914.

Fuller-Rowell, T. J., D. Rees, S. Quegan, R. J. Moffett, M. V. Codrescu, and G. H. Millward (1996a), A coupled thermosphere ionosphere model (CTIM), in Handbook of Ionospheric Models, STEP Rep., edited by R. W. Schunk, pp. 217-238, Utah State Univ., Logan, Utah.

Fuller-Rowell, T. J., M. V. Codrescu, H. Rishbeth, R. J. Moffett, and S. Quegan (1996b), On the seasonal response of the thermosphere and ionosphere to geomagnetic storms, J. Geophys. Res., 101, 2343-2353.

Hays, P. B., and R. G. Roble (1971), Direct observations of thermospheric winds during geomagnetic storms, J. Geophys. Res., 76, 5316-5321.

Hays, P. B., J. W. Meriwether, and R. G. Roble (1979), Nighttime thermospheric winds at high latitudes, J. Geophys. Res., 84, 1905-1913.

Hays, P. B., T. L. Killeen, N. W. Spencer, L. E. Wharton, R. G. Roble, B. A. Emery, T. J. Fuller-Rowell, D. Rees, L. A. Frank, and J. D. Craven (1984), Observations of the dynamics of polar thermosphere, J. Geophys. Res., 89, 5597-5612.

Hedin, A. E., N. W. Spencer, and T. L. Killeen (1988), Empirical global model of upper Thermosphere winds based on atmosphere and Dynamics Explorer satellite data, J. Geophys. Res., 93, 9959-9978.

Hedin, A. E., et al. (1991), Revised global model of thermosphere winds using satellite and ground-based observations, J. Geophys. Res., 96, $7657-7688$

Hedin, A. E., et al. (1996), Empirical wind model for the Upper, middle and lower atmosphere, J. Atmos. Terr. Phys., 58, 1421-1447.

Ishii, M., M. Conde, R. W. Smith, M. Krynicki, E. Sagawa, and S. J. Watari (2001), Vertical winds observations with two Fabry-Pérot interferometers at Poker Flat, Alaska, J. Geophys. Res., 106, 10,537-10,552.

Ishii, M., M. Kubota, M. Conde, R. W. Smith, and M. Krynicki (2003), Horizontal distributions of thermospheric vertical winds in the polar regions, Eos Trans. $A G U, 84(46)$, Fall Meet. Suppl., Abstract SA21A-06.

Ishii, M., M. Kubota, M. Conde, R. W. Smith, and M. Krynicki (2004), Vertical wind distribution in the polar thermosphere during Horizontal E Region Experiment campaign., J. Geophys. Res., 109, A12311, doi:10.1029/2004JA010657.

Innis, J. L., and M. Conde (2001), Thermospheric vertical wind activity maps from Dynamics Explorer 2 WATS observations, Geophys. Res. Let., $28,3847-3850$.

Innis, J. L., and M. Conde (2002), High-latitude thermospheric vertical wind activity from Dynamics Explorer 2 Wind and temperature Spectrometer observations: Indications of a source for polar cap gravity waves, J. Geophys. Res., 107(A8), 1172, doi:10.1029/2001JA009130.

Killeen, T. L., P. B. Hays, N. W. Spencer, and L. E. Wharton (1982), Neutral winds in the polar thermosphere as measured from Dynamics Explorer, Geophys. Res. Lett., 9, 957-960.

King-Hele, G. G., and D. M. C. Walker (1983), Upper-atmosphere zonal winds from satellite orbit analysis, Planet. Space Sci., 31, 509-535. 
Lathuillère, C., J. Lilensten, W. A. Gault, and G. Thuillier (1997), The meridional wind in the auroral thermosphere: Results from EISCAT and WINDII-O1D coordinated measurements, J. Geophys. Res., 102, 4487-4492

Lilensten, J., and C. Lathuillère (1995), The meridional thermospheric neutral wind measured by the EISCAT radar, J. Geomagn. Geoelectr. 47, 911-920.

Lilensten, J., G. Thuillier, C. Lathuillère, K. Kofman, V. Fauliot, and M. Hersé (1992), EISCAT-MICADO coordinated measurements of meridional wind, Ann. Geophys., 10, 603-618.

Meriwether, J. W., J. P. Heppner, J. D. Stolarik, and E. M. Wescott (1973), Neutral winds above $200 \mathrm{~km}$ at high latitudes, J. Geophys. Res., 78, $6643-6661$

Millward, G. H., R. J. Moffett, S. Quegan, and T. J. Fuller-Rowell (1996), A coupled thermosphere ionosphere plasmasphere model (CTIP), in Handbook of Ionospheric Models, STEP Rep., edited by R. W. Schunk, pp. 238-279, Utah State Univ., Logan, Utah.

Nagy, A. F., R. J. Cicerone, P. B. Hays, K. D. McWatters, J. W. Meriwether A. E. Belon, and C. L. Rino (1974), Simultaneous measurement of ion and neutral motions by radar and optical techniques, Radio Sci., 9, 315321.

Quegan, S., G. J. Bailey, R. J. Moffett, R. A. Heelis, T. J. Fuller-Rowell, D. Rees, and R. W. Spiro (1982), A theoretical study of the distribution of ionization in the high-latitude ionosphere and plasmasphere: First results on the mid-latitude trough and the light ion trough, J. Atmos. Terr. Phys., 44, 619.

Richmond, A. D., and R. G. Roble (1987), Electrodynamic effects of thermospheric winds from the NCAR thermospheric general circulation model, J. Geophys. Res., 92, 12,365-12,376.

Rees, D. (1969), Vertical winds in the lower ionosphere, J. Brit. Interplan. Soc., 22, 275-284.

Rees, D. (1972), Winds and temperature in the auroral zone and their relation to geomagnetic activity, Phil. Trans. R. Soc. London, Ser. A, $271,563-575$.

Rees, D. (1993), A review of the dynamics of the lower and upper thermosphere, in Flow and Creep in the Solar System: Observations, Modelling and Theory, edited by D. B. Stone and S. K. Runcorn, pp. 13-44, Springer, New York.

Rees, D., R. W. Smith, F. Siguernes, K. Henriksen, U. Brandstrom, M. Harris, and G. Maskall (1998), Observations of thermospheric winds neutral winds within the polar cap and the auroral zone using a Doppler Imaging System (DIS), Ann. Geophys., 16, 1461-1474.
Smith, R. W., and P. J. Sweeney (1980), Winds in the thermosphere of the northern polar cap, Nature, 284, 437-438

Smith, R. W., G. Hernandez, K. Price, G. Fraser, K. C. Clark, W. J. Schulz, S. Smith, and M. Clark (1994), The June 1991 thermospheric storm observed in the Southern Hemisphere, J. Geophys. Res., 99, 17,60917,615 .

Spencer, N. W. L. E. Wharton, H. B. Niemann, A. E. Hedin, G. R. Carignan, and J. C. Maurer (1981), The Dynamics Explorer Wind And Temperature Spectrometer, Space Sci. Instrum., 5, 417-428.

Steele, D. P., D. J. McEwen, and G. G. Sivjee (1998), Ground-based optical observations from the north magnetic pole during the January 1997 magnetic cloud event, Geophys. Res. Lett., 25, 2573-2576.

Thuillier, G., and M. Hersé (1991), Thermally stable field compensated Michelson interferometer for measurement of temperature and wind of the planetary atmospheres, Appl. Opt., 30, 1210-1220.

Thuillier, G., C. Lathuillère, M. Hersé, C. Senior, W. Kofman, M. L. Duboin, D. Alcaydé, F. Barlier, and J. Fontanari (1990), Co-ordinated EISCAT-MICADO interferometer measurements of neutral winds and temperatures in E- and F-regions, J. Atmos. Terr. Phys., 52, 625636.

Weimer, D. R. (1996), A flexible, IMF dependent model of high-latitude electric potentials having space weather applications, Geophys. Res. Lett., $6,21-24$.

Witasse, O., J. Lilensten, C. Lathuillère, and B. Pibaret (1998), Meridional thermospheric neutral wind at high latitude over a full solar cycle, Ann. Geophys., 16, 1400-1409.

Wu, S. T., S. Matsushita, and L. L. DeVries (1974), An analysis of the upper atmospheric wind observed by LOGACS, Planet. Space Sci., 22, $1036-1041$

M. Codrescu and T. Fuller-Rowell, Cooperative Institute for Research in Environmental Sciences, University of Colorado, Boulder, CO 80302 , USA.

M. Fehrenbach, F. Huppert, and J.-M. Perrin, Observatoire de Haute Provence, F-04870 St Michel l'Observatoire, France.

M. Hersé and G. Thuillier, Service d'Aéronomie du Centre National de la Recherche Scientifique, F-91371 Verrières-le-Buisson, France. (gerard. thuillier@aerov.jussieu.fr)

C. Lathuillère, Laboratoire de Planétologie de Grenoble, F-38041 Grenoble, France 

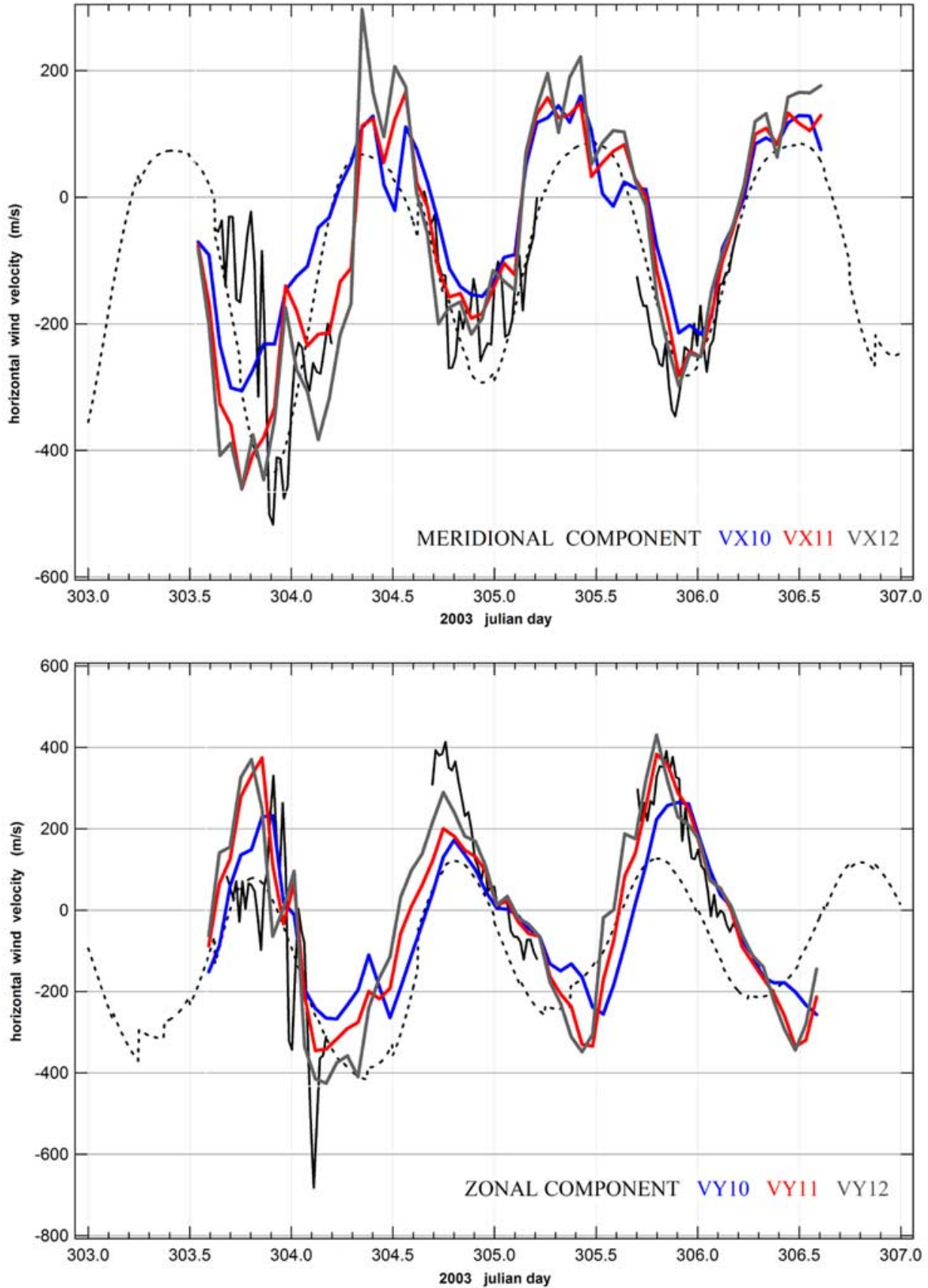

Figure 10. Comparison between the wind observed by EPIS (dash line) and the calculated wind (solid line) using the CTIPe model. The velocity is calculated at three levels denoted VX10, VX11, VX12 for the meridional component (upper panel), and VY10, VY11, VY12 for the zonal component (lower panel). 